\title{
INFLUÊNCIA DAS FLORESTAS URBANAS NA VARIAÇÃO TERMO-HIGROMÉTRICA DA ÁREA INTRAURBANA DE CURITIBA - PR
}

\author{
INFLUENCE OF URBAN FORESTS IN THE THERMO-HYGROMETRIC VARIATION IN THE \\ INTRA-URBAN AREA OF THE CITY OF CURITIBA - PARANÁ STATE
}

\author{
Luciana Leal ${ }^{1}$ Daniela Biondi ${ }^{2}$ Antonio Carlos Batista ${ }^{3}$
}

\begin{abstract}
RESUMO
De modo a entender a influência das florestas urbanas na variação termo-higrométrica da área intraurbana da cidade de Curitiba, este trabalho teve como objetivo analisar a variação temporal e espacial da temperatura e da umidade relativa do ar em cada estação do ano e relacioná-la com a presença das florestas urbanas. Para a coleta dos dados meteorológicos foram estabelecidos 44 pontos de monitoramento em quatro transectos na malha urbana da cidade. Nestes pontos foram instalados miniabrigos meteorológicos com sensores modelo Hobo ${ }^{\circledR}$, fixados nas hastes de sinaleiros e placas de sinalização. O monitoramento da temperatura e umidade relativa do ar foi realizado em períodos correspondentes às quatro estações do ano, com 22 dias de coleta e registro contínuo de dados em intervalos de 15 minutos. Nos quatro transectos analisados na área intraurbana de Curitiba foram encontradas diferenças termo-higrométricas significativas entre os pontos de monitoramento em todos os períodos analisados. Mesmo nas estações do ano de mais baixas temperaturas, o outono e o inverno, foram encontradas diferenças térmicas, relacionadas ao calor antropogênico. Pela análise do perfil longitudinal das temperaturas, observou-se curva semelhante ao perfil clássico das ilhas de calor urbano, com as maiores temperaturas nos locais com maior intensidade de ocupação e atividades antrópicas, como na área central e região centro-sul. As menores temperaturas foram encontradas em bairros residenciais e periféricos, como nas porções norte e noroeste do município e limite sul, além de se evidenciar o efeito do resfriamento das florestas urbanas presentes na área intraurbana, como os Parques Municipais Barigui e São Lourenço. As regiões com maior quantidade de áreas permeáveis, concentração de remanescentes florestais ou espaços verdes públicos apresentaram menores temperaturas e aumento da umidade relativa do ar.
\end{abstract}

Palavras-chave: arborização urbana; microclima urbano; temperatura do ar.

\begin{abstract}
In order to understand the influence of urban forests in the thermo-hygrometric variation in the intra-urban area of the city of Curitiba, this study aimed to analyze the temporal and spatial variation of temperature and relative air humidity in each season and relate it with the presence of urban forests. For the collection of meteorological data were established 44 monitoring points in four transects in the urban mesh. In these points, mini-shields with Hobo ${ }^{\circledR}$ loggers were installed at fixed points on sign and traffic light posts. The temperature and relative air humidity monitoring was conducted during periods corresponding to the four seasons, with 22 days to collect and continuous data record at 15 minute intervals. In the four transects analyzed in the intra-urban area of Curitiba significative differences were found between the thermohygrometric monitoring points in all periods analyzed. Even in seasons of lower temperatures, autumn

1 Engenheira Florestal, Dra ${ }^{\mathrm{a}}$, Analista Ambiental da Companhia Paranaense de Energia, Rua Comendador Araújo, 614, Batel, CEP 80420-000, Curitiba (PR), Brasil. luciana_paisagem@yahoo.com.br

2 Engenheira Florestal, Dr ${ }^{\text {a. }}$, Professora Associada Departamento Ciências Florestais, Universidade Federal do Paraná, Av. Lothário Meissner, 632, Jardim Botânico, CEP 80210-170, Curitiba (PR), Brasil. Pesquisadora Bolsista de Produtividade em Pesquisa do CNPq. dbiondi@ufpr.br

3 Engenheiro Florestal, Dr., Professor Associado Departamento Ciências Florestais, Universidade Federal do Paraná, Av. Lothário Meissner, 632, Jardim Botânico, CEP 80210-170, Curitiba (PR), Brasil. Pesquisador Bolsista de Produtividade em Pesquisa do CNPq. batistaufpr@ufpr.br
\end{abstract}

Recebido para publicação em 24/12/2012 e aceito em 13/05/2013 
and winter, thermal differences were related to anthropogenic heat. The analysis of the longitudinal profile of the temperature revealed a curve similar to classic profile of urban heat islands, with the highest temperatures in more densely occupied areas and human activities, such as in the city center and southcenter area. The lowest temperatures were found in residential districts and the suburbs, such as in the north and northwest areas of the city and the southern city border, in addition to the evidence of the cooling effect of urban forests present in the intra-urban area, as 'Barigui' and 'São Lourenço Parks'. The regions with the largest of permeable areas, concentration of forest remnants or public green space had lower temperatures and increased the relative air humidity.

Keywords: urban trees; urban microclimate; air temperature.

\section{INTRODUÇÃO}

As cidades possuem um clima local distinto, caracterizado por apresentar temperaturas mais elevadas nas áreas densamente construídas quando comparadas com seu entorno. O local da cidade com maior atividade antrópica, normalmente o centro, se caracteriza por ser mais quente que os bairros residenciais e periféricos (OKE, 1974).

As cidades frequentemente compreendem um mosaico de áreas com diferentes temperaturas, conforme a variação da cobertura do solo urbano. As temperaturas na mancha urbana apresentamse, muitas vezes, mais altas do que nas áreas rurais circunvizinhas, enquanto que, no interior da cidade, as variações térmicas ocorrem principalmente entre os espaços livres e os vegetados e as áreas construídas, produzindo defasagens de temperaturas intraurbanas em até $7^{\circ} \mathrm{C}$ (UPMANIS; ELIASSON; LINDQVIST, 1998; SPROKEN-SMITH; OKE, 1999; ELIASSON, 2000). A área urbana pode apresentar valores de umidade relativa do ar menores em mais de $40 \%$ do que seus arredores, mas diferenças da ordem de 20 a $30 \%$ são mais típicas (FORTUNIAK; KLYSIK; WIBIG, 2006).

Dentro da cidade, as diferenças termohigrométricas apresentam variabilidade espacial e temporal (GRIMMOND, 2007). Se de um lado as áreas mais artificializadas da cidade, como é o caso do centro, produzem maiores alterações no clima local, por outro, as áreas que mais se aproximam das condições ambientais normais da natureza, ou seja, lugares mais arborizados apresentam um clima diferenciado e, por consequência, mais ameno. Medidas como a arborização de vias públicas, praças, vazios urbanos destinados a áreas verdes, encostas e fundos de vale podem contribuir significativamente para amenização do clima urbano (GOMES; AMORIM, 2003).

Yu e Hien (2006) consideram que o plantio de árvores em áreas urbanas é uma medida efetiva para criar um efeito de "oásis" e mitigar o aquecimento urbano nos níveis macro e micro. Quando a vegetação da cidade é distribuída em reservas naturais, parques urbanos, parques metropolitanos, jardins e assim por diante, o balanço de energia de toda a cidade pode ser modificado pela adição de mais superfícies evaporativas, mais radiação absorvida pode ser dissipada na forma de calor latente e a temperatura urbana pode ser reduzida.

A cidade de Curitiba, capital do estado do Paraná, tem aspectos interessantes e características bem definidas para estudos de clima urbano, em virtude dos diferentes usos do solo, ordenados pelo zoneamento que estabelece parâmetros de ocupação e pela quantidade de diferentes tipos de florestas urbanas com distribuição irregular em sua área intraurbana.

Pesquisas realizadas com técnicas de sensoriamento remoto termal mostram que o aglomerado urbano da cidade de Curitiba apresenta diferenças térmicas intraurbanas, embora se destaque como uma mancha mais quente e homogênea do que a área rural circunvizinha (MENDONÇA; DUBREUIL, 2005; DUMKE, 2007). Nestas pesquisas é apresentada genericamente a influência da vegetação sobre o clima local, porém, não há informações sobre como a sua distribuição e características afetam o microclima.

Considerando que a distribuição e o arranjo das florestas urbanas influenciam de maneira distinta o clima dos diferentes setores da área intraurbana de Curitiba, este trabalho teve como objetivo analisar a variação temporal e espacial da temperatura e da umidade relativa do ar em cada estação do ano e relacioná-la com a presença das florestas urbanas. 


\section{MATERIAL E MÉTODOS}

\section{Área de estudo}

O município de Curitiba - PR, localizado na região sul do Brasil e fundado no ano de 1693, ocupa o espaço geográfico de $432,17 \mathrm{~km}^{2}$ de área, na latitude $25^{\circ} 25^{\prime} 40^{\prime} \mathrm{S}$ e longitude $49^{\circ} 16^{\prime} 23^{\prime \prime} \mathrm{W}$ (Marco Zero na Praça Tiradentes). A extensão do município é de $20 \mathrm{~km}$ de leste a oeste e de $35 \mathrm{~km}$ de norte a sul.

O clima de Curitiba apresenta médias térmicas que variam de $12,9^{\circ} \mathrm{C}$, no mês mais frio, a $22,5^{\circ} \mathrm{C}$, no mês mais quente, com temperatura média de $16,4^{\circ} \mathrm{C}$ e precipitações médias anuais de $1600 \mathrm{~mm}$ (MENDONÇA; DANNI-OLIVEIRA, 2007).

A Prefeitura Municipal de Curitiba (2011), em levantamento realizado no ano de 2010, divulgou o total de 113 milhões $\mathrm{m}^{2}$ de áreas verdes, com índice de $64,5 \mathrm{~m}^{2}$.habitante ${ }^{-1}$. Vieira e Biondi (2008), no entanto, citam que as florestas urbanas são distribuídas irregularmente pelo município, com concentração da maioria dos parques e bosques na porção norte.

As disposições urbanísticas de ocupação e uso do solo são regidas pelo zoneamento em vigor, o qual foi fixado pela Lei Municipal $n^{\circ}$ 9.800/2000 e decretos complementares, com configuração que inclui Zona Central, Zonas Residenciais, Zonas de Serviço, Zonas Industriais, Setores de Interesse Socioeconômico e Setores Especiais de Interesse Ambiental, dentre outros (INSTITUTO DE PESQUISA E PLANEJAMENTO URBANO DE CURITIBA, 2012).

\section{Procedimentos metodológicos}

A escala horizontal de análise considerada foi o clima local, que, conforme Andrade (2005), designa o clima das áreas homogêneas quanto à ocupação do solo ou condições topográficas, cuja dimensão pode variar de algumas dezenas a centenas de metros, segundo World Meteorological Organization (2008), em áreas urbanas significa o clima de bairros com tipo similar de desenvolvimento urbano.

A escala vertical se refere a urban canopy layer (camada urbana ao nível das coberturas) que compreende o espaço entre o solo e o nível médio das coberturas das edificações e representa a interação entre a atmosfera e os elementos urbanos
(OKE, 1976).

A vegetação foi analisada de acordo com o conceito de florestas urbanas (MILLER, 1997; GONÇALVES; PAIVA, 2006), considerando-se os vários espaços que podem ser ocupados por um aglomerado de indivíduos arbóreos na área urbana.

As variáveis meteorológicas medidas foram: temperatura e umidade relativa do ar. Estas variáveis foram coletadas com sensores meteorológicos modelo Hobo ${ }^{\circledR}$, marca Onset, previamente aferidos, que medem temperaturas entre -20 e $70^{\circ} \mathrm{C}$ e umidade relativa entre 25 e 95\% e têm capacidade de armazenar 7944 dados. A precisão é de \pm 5 unidades para umidade relativa e $\pm 0,7$ unidades (melhor resolução $\pm 0,4$ ) para temperatura.

Para instalação em campo, os sensores foram colocados em miniabrigos meteorológicos, confeccionados com uma seção de tubo de PVC, medindo $150 \mathrm{~mm}$ de comprimento e $100 \mathrm{~mm}$ de diâmetro, com aberturas nas laterais e revestidos externamente com papel alumínio. Para o fechamento foram utilizadas duas tampas e no tubo foram feitos dois furos para permitir a colocação da fita abraçadeira de nylon para fixação.

Os miniabrigos meteorológicos foram instalados em 44 pontos de monitoramento, em locais fixos na área intraurbana de Curitiba, limitando-se à malha urbana. Para isto foram definidos quatro transectos cruzando um ponto central na Praça Tiradentes (marco zero da cidade), estabelecendo-se 15 pontos no transecto nortesul, 10 pontos no transecto leste-oeste, 12 pontos no transecto sudoeste-nordeste e 10 pontos no transecto noroeste-sudeste. A distância estabelecida entre os pontos de monitoramento variou de $1,5 \mathrm{~km}$ (transectos norte-sul e leste-oeste) a $2 \mathrm{~km}$ (transectos sudoeste-nordeste e noroeste-sudeste). Optou-se por um maior adensamento de pontos na área central da cidade, formando-se um anel ao redor do ponto central, similar ao padrão de distribuição utilizado por Kolokotroni, Giannitsaris e Watkin (2006) na cidade de Londres, Inglaterra.

$\mathrm{Na}$ escolha dos locais para a instalação dos miniabrigos meteorológicos foram considerados os critérios de padronização, fácil acesso e segurança durante os períodos de coleta de dados. Estes foram instalados nas hastes dos sinaleiros e placas de sinalização, o que atenderia aos critérios elencados, com a autorização da Urbanização de Curitiba S.A. - URBS para uso das estruturas urbanas de responsabilidade deste órgão. 
Para locação dos pontos de monitoramento, elaborou-se uma grade sob o mapa da cidade de Curitiba, em escala 1:20.000, localizando-os nos cruzamentos entre ruas, com posterior verificação em campo. Na escolha dos pontos evitaram-se estruturas muito próximas a árvores ou obstruções de construções, como prédios e paredes. Os pontos estabelecidos, apresentados na Figura 1, estão descritos detalhadamente em Leal (2012).

A instalação dos equipamentos foi realizada no topo da haste dos sinaleiros ou placas de sinalização a uma altura média de $4 \mathrm{~m}$ do solo. Segundo World Meteorological Organization(2008), há flexibilidade para coletar dados meteorológicos em áreas urbanas em alturas maiores ( 3 a $5 \mathrm{~m}$ ) daquelas coletadas na altura padrão $(1,25$ a $2 \mathrm{~m})$, sem necessidade de correção de dados, tendo maior cobertura footprints e localizando o sensor em área de difícil alcance, prevenindo danos por vandalismo, além de assegurar maior diluição do calor de exaustão de veículos e reduzir a contaminação pela poeira.

Os dados meteorológicos foram coletados em quatro campanhas, cada uma com duração de 22 dias, em períodos correspondentes às estações do ano em 2011: verão ( 7 a 28 de fevereiro), outono ( 9 a 30 de maio), inverno ( 4 a 25 de agosto) e primavera ( 3 a 24 de novembro). A coleta contínua de dados foi realizada em intervalos de 15 minutos, totalizando 2112 leituras de cada variável por período, de modo a incluir diferentes condições de tempo.

As médias de temperatura e umidade relativa do ar, em cada estação do ano, foram avaliadas pelo teste de F e comparadas pelo teste de Duncan a $5 \%$ de significância. Também foram calculadas as diferenças térmicas e higrométricas entre os pontos de monitoramento em cada transecto.

Os resultados foram analisados a partir da caracterização qualitativa dos pontos de monitoramento quanto à presença de florestas

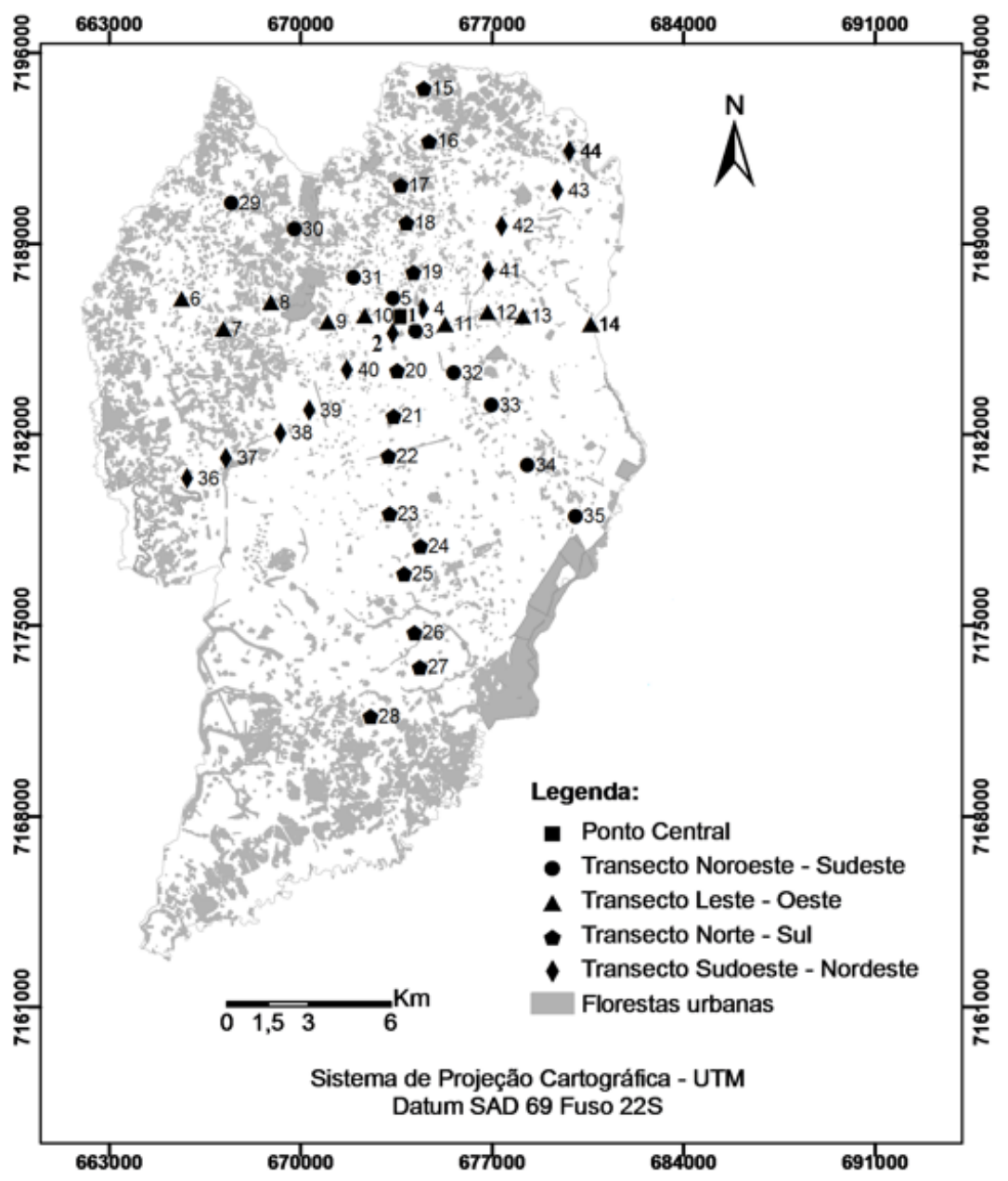

FIGURA 1: Localização dos pontos de monitoramento na área intraurbana de Curitiba. FIGURE 1: Location of monitoring points in the intra-urban area of Curitiba. 
urbanas e classe de zoneamento do uso do solo, por meio de informações bibliográficas, cartográficas e dados adicionais obtidos in loco, considerando-se um raio de $500 \mathrm{~m}$ de cada miniabrigo meteorológico instalado, conforme Oke (2007).

\section{RESULTADOS E DISCUSSÃO}

\section{Variação termo-higrométrica no transecto norte sul}

No transecto norte-sul, a maior diferença térmica foi encontrada no período correspondente ao outono $\left(1,7^{\circ} \mathrm{C}\right.$ ), entre os pontos $\mathrm{P} 16$ (Avenida Anita Garibaldi com Rua Flávio Dallegrave Bairro Barreirinha) e P20 (Rua Brasílio Itiberê com Rua Brigadeiro Franco - Bairro Rebouças), enquanto que nas outras estações do ano as maiores diferenças ocorreram entre os pontos P15 (Avenida Anita Garibaldi com Rua Rolando Salin Zappa Mansur - Bairro Cachoeira) e P20, com diferenças térmicas de 1,2 a $1,6^{\circ} \mathrm{C}$ (Tabela 1). As diferenças térmicas significativas foram observadas inclusive nos períodos do outono e inverno, quando ocorreram as menores temperaturas, o que está relacionado ao calor antropogênico, gerado por edifícios, processos industriais, veículos ou até mesmo as próprias pessoas, geralmente maior no inverno do que no verão, conforme Gartland (2010).

Os pontos P15 e P16 localizam-se em um dos extremos deste transecto (lado norte). O ponto P15 está localizado em Zona Residencial de Ocupação Controlada (ZR-OC), onde existe grande concentração de florestas urbanas, dentre estas, o Parque Municipal Nascentes do Belém e o ponto P16, em Zona Residencial de Baixa Densidade (ZR2) e entre os dois pontos está o Parque Municipal da Barreirinha. A baixa densidade de construção e a presença das florestas urbanas explicam as menores temperaturas encontradas. Já o ponto P20 está localizado em área entre as Zonas Residenciais de Média-Alta Densidade (ZR-4) e de Média Densidade (ZR-3), com tipologias de florestas urbanas limitadas às praças, aos jardinetes e à arborização de ruas.

Destacaram-se ainda, pelas maiores

TABELA 1: Temperatura média e umidade relativa do ar média no transecto norte-sul na área intraurbana de Curitiba nos períodos correspondentes às estações do ano de 2011.

TABLE 1: Average temperature and average relative humidity in the north-south transect in the intra-urban area of Curitiba corresponding periods in the seasons of 2011.

\begin{tabular}{|c|c|c|c|c|c|c|c|c|c|c|c|c|c|c|c|c|}
\hline \multirow{2}{*}{ Períodos } & \multicolumn{15}{|c|}{ Pontos de monitoramento } & \multirow{2}{*}{ Diferenças } \\
\hline & P15 & P16 & P17 & $\mathrm{P} 18$ & P19 & P1 & $\mathrm{P} 20$ & $\mathrm{P} 21$ & P22 & P23 & P24 & P25 & $\mathrm{P} 26$ & P27 & P28 & \\
\hline \multicolumn{16}{|c|}{ Temperatura média do ar $\left({ }^{\circ} \mathrm{C}\right)$} & Térmicas \\
\hline Verão & 20,8 & 21,4 & 21,2 & 22,0 & 21,6 & 21,9 & 22,0 & 22,0 & 21,5 & 21,3 & 21,6 & 21,7 & 21,8 & 21,0 & 21,0 & \multirow{2}{*}{1,2} \\
\hline (2) & $\mathrm{a}$ & $\mathrm{cd}$ & bc & $\mathrm{h}$ & cde & gh & $\mathrm{h}$ & $\mathrm{h}$ & $\mathrm{cd}$ & $\mathrm{c}$ & $\mathrm{cd}$ & efg & fgh & $\mathrm{b}$ & $\mathrm{b}$ & \\
\hline \multirow{2}{*}{ Outono } & 14,6 & 13,9 & 14,2 & 14,9 & 14,5 & 15,3 & 15,6 & 15,2 & 14,9 & 14,6 & 14,9 & 15,0 & 15,0 & 14,7 & 14,2 & \multirow{2}{*}{1,7} \\
\hline & $\mathrm{c}$ & $\mathrm{a}$ & $\mathrm{b}$ & de & $\mathrm{c}$ & $\mathrm{g}$ & $\mathrm{h}$ & $\mathrm{fg}$ & de & $\mathrm{c}$ & de & efg & ef & $\mathrm{cd}$ & $\mathrm{b}$ & \\
\hline \multirow{2}{*}{ Inverno } & 14,0 & 14,5 & 14,1 & 14,6 & 14,5 & 15,0 & 15,2 & 14,9 & 14,6 & 14,3 & 14,6 & 14,6 & 14,6 & 14,3 & 14,0 & \multirow{2}{*}{1,2} \\
\hline & $\mathrm{a}$ & $\mathrm{bc}$ & $\mathrm{ab}$ & $\mathrm{cd}$ & $\mathrm{bc}$ & $\mathrm{e}$ & $\mathrm{e}$ & de & $\mathrm{cd}$ & $a b c$ & $\mathrm{~cd}$ & $\mathrm{~cd}$ & $\mathrm{~cd}$ & $a b c$ & $\mathrm{a}$ & \\
\hline \multirow{2}{*}{ Primavera } & 16,8 & 17,9 & 17,4 & 18,3 & 17,9 & 18,3 & 18,4 & 18,3 & 17,6 & 17,5 & 18,0 & 18,2 & 18,1 & 17,5 & 17,3 & \multirow{2}{*}{1,6} \\
\hline & $\mathrm{a}$ & $\mathrm{cd}$ & $\mathrm{b}$ & $\mathrm{f}$ & $\mathrm{cd}$ & ef & $\mathrm{f}$ & ef & $\mathrm{bc}$ & $\mathrm{b}$ & de & def & $\operatorname{def}$ & $\mathrm{b}$ & $\mathrm{b}$ & \\
\hline \multicolumn{16}{|c|}{ Umidade relativa do ar $(\%)$} & Higrométrica \\
\hline \multirow{2}{*}{ Verão } & 86 & 85 & 85 & 83 & 82 & 82 & 82 & 83 & 83 & 83 & 83 & 83 & 83 & 83 & 87 & \multirow{2}{*}{5} \\
\hline & a & $\mathrm{b}$ & $\mathrm{b}$ & $\mathrm{c}$ & cd & $\mathrm{cd}$ & $\mathrm{cd}$ & $\mathrm{c}$ & $\mathrm{c}$ & $\mathrm{c}$ & $\mathrm{c}$ & $\mathrm{c}$ & $\mathrm{c}$ & $\mathrm{c}$ & $\mathrm{a}$ & \\
\hline \multirow{2}{*}{ Outono } & 81 & 86 & 85 & 82 & 81 & 79 & 79 & 82 & 84 & 81 & 81 & 78 & 81 & 81 & 83 & \multirow{2}{*}{8} \\
\hline & fg & $\mathrm{a}$ & b & ef & efg & $\mathrm{g}$ & $\mathrm{g}$ & efg & bc & $\mathrm{fg}$ & fg & $\mathrm{g}$ & $\mathrm{fg}$ & $\mathrm{fg}$ & $\mathrm{cd}$ & \\
\hline \multirow{2}{*}{ Inverno } & 86 & 89 & 91 & 91 & 88 & 84 & 88 & 89 & 91 & 88 & 87 & 86 & 88 & 89 & 90 & \multirow{2}{*}{7} \\
\hline & de & $a b$ & $\mathrm{a}$ & $\mathrm{a}$ & $\mathrm{bc}$ & $\mathrm{e}$ & $\mathrm{bc}$ & $\mathrm{bc}$ & $a b$ & bc & $\mathrm{cd}$ & de & bc & $\mathrm{bc}$ & $a b$ & \\
\hline \multirow{2}{*}{ Primavera } & 76 & 78 & 75 & 74 & 73 & 73 & 74 & 75 & 78 & 75 & 74 & 72 & 74 & 74 & 76 & \multirow{2}{*}{7} \\
\hline & $\mathrm{a}$ & $\mathrm{a}$ & $\mathrm{b}$ & bcd & $\mathrm{cd}$ & $\mathrm{cd}$ & bcd & bcd & $\mathrm{a}$ & bc & $\mathrm{cd}$ & $\mathrm{d}$ & bcd & bcd & $\mathrm{a}$ & \\
\hline
\end{tabular}

Em que: Médias seguidas pela mesma letra na linha (estação do ano) não diferem estatisticamente a 5\% de significância pelo teste de Duncan. 
temperaturas, os pontos P1 (Praça Tiradentes), P21 (Avenida Presidente Kennedy com Rua Minas Gerais - Guaíra) e P18 (Rua Mateus Leme - São Lourenço) (Tabela 1), localizados em área central ou bastante urbanizada e com alto fluxo de veículos.

Mesmo no verão, período influenciado pelas chuvas localizadas, em que as diferenças higrométricas encontradas foram de apenas cinco unidades (Tabela 1), verificaram-se diferenças estatísticas significativas entre os pontos de monitoramento, com os pontos localizados nos extremos do transecto apresentando os maiores valores de umidade relativa do ar.

Pelo perfil das temperaturas médias, apresentado na Figura 2, verificou-se curva semelhante ao perfil clássico das ilhas de calor urbano, descrito por Oke (1974), com o pico (as maiores temperaturas) na área mais urbanizada da cidade (pontos P1, P20 e P21) e as menores temperaturas nos pontos extremos - limites norte e sul da cidade (pontos P15 - Av. Anita Garibaldi com Rua Rolando Salin Zappa Mansur, Bairro Cachoeira e P28 - Rua Nicola Pelanda, Umbará), ambos em Zona Residencial de Ocupação Controlada (ZR$\mathrm{OC})$, com grande concentração de vegetação. Foi verificada diminuição gradativa da temperatura, conforme aumenta a distância do centro, chamada de plateau, os espaços verdes urbanos proporcionaram descontinuidades mais bruscas nos valores de temperatura. As quebras de continuidade das altas temperaturas na área intraurbana ocorreram na região norte, nos pontos P17 (Rua João Gava com Rua Antonio Krainiski - Abranches) e P19 (Rua Deputado Mário de Barros com Raul Viana - Centro

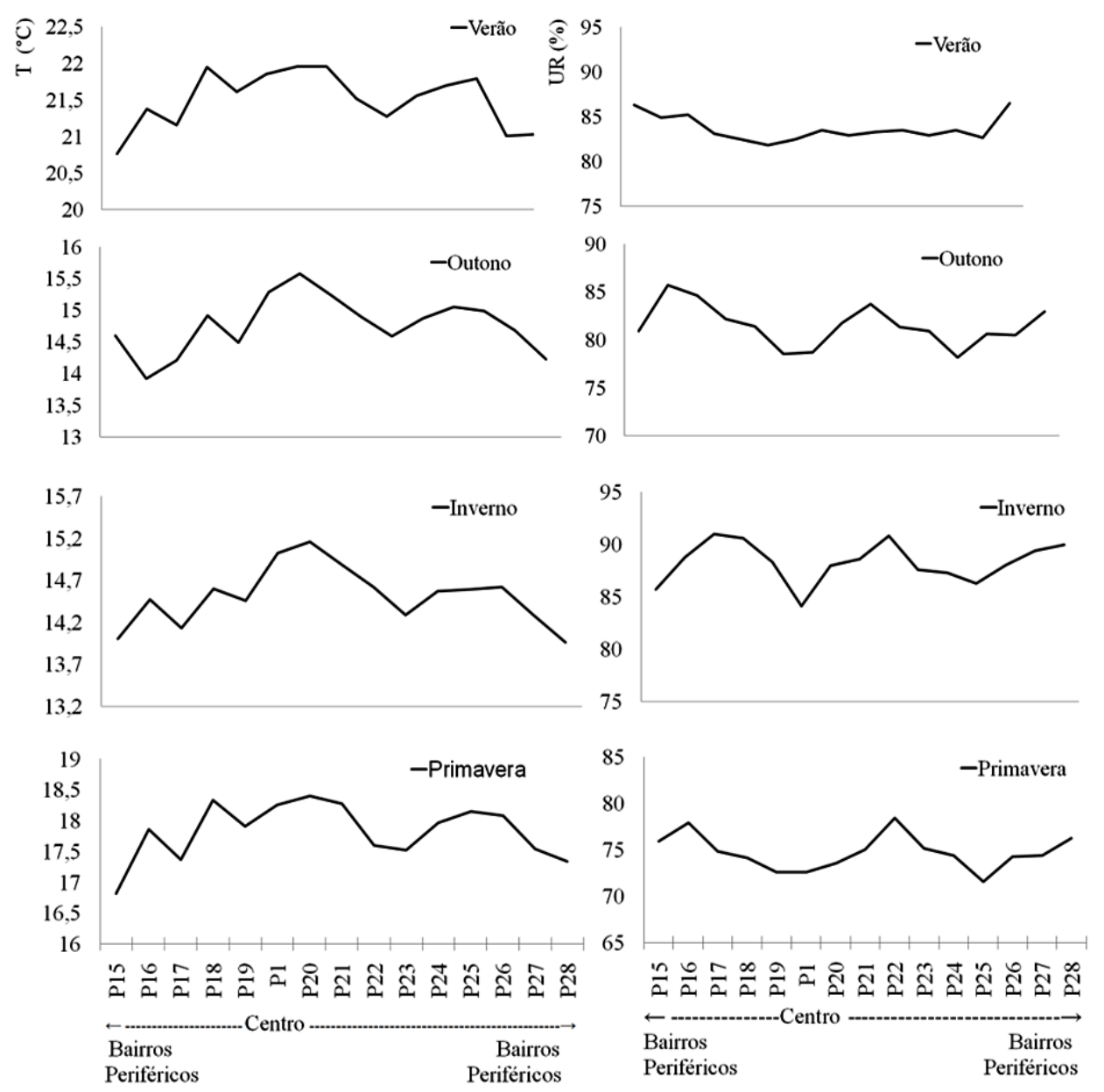

FIGURA 2: Perfil longitudinal da temperatura média e umidade relativa do ar média no transecto norte-sul na área intraurbana de Curitiba no ano de 2011.

FIGURE 2: Longitudinal profile of the average temperature and average relative humidity in the northsouth transect in the intra-urban area of Curitiba in 2011. 
Cívico), e na porção centro-sul da cidade, nos pontos P22 (Rua Wenceslau Braz com Rua Camilo Castelo Branco - Bairro Lindoia) e P23 (Rua Deputado Neo Martins com Linha Verde (BR 116) - Bairro Fanny). A umidade relativa do ar média apresentou, em geral, comportamento inverso ao da temperatura média do ar, com menores valores na área mais urbanizada e os maiores valores nos pontos extremos do transecto e próximos de florestas urbanas.

A alteração da temperatura do ar nos pontos P17 e P19 e o aumento da umidade relativa do ar podem ser explicados pela presença das florestas urbanas. Os Parques São Lourenço, com área de $203.918 \mathrm{~m}^{2}$, e das Pedreiras, com área de 103.500 $\mathrm{m}^{2}$, estão localizados próximos ao ponto $\mathrm{P} 17$, e o Bosque João Paulo II (Bosque do Papa), com área de $48.000 \mathrm{~m}^{2}$, nas proximidades do ponto P19. Isto mostra o papel significativo dos parques urbanos no microclima local, assim como verificado por Dimoudi e Nikolopoulou (2003), Wong e Yu (2005) e Yu e Hien (2006).

O ponto P22 localiza-se junto ao Eixo de Animação Arnaldo Faivro Buzzato, com área de $103.200 \mathrm{~m}^{2}$, com canteiro gramado e arborização com espécie de grande porte, Tipuana tipu (Benth.) Kuntze (tipuana). Isto demonstra o efeito positivo desta categoria de floresta urbana na região, que, embora apresente, muitas vezes, menor área ocupada com vegetação arbórea do que os parques e bosques, ainda assim influencia o microclima urbano.

Outro aspecto que pode ter influenciado para a diminuição das temperaturas e o aumento da umidade relativa do ar no ponto $\mathrm{P} 22$, e também no ponto $\mathrm{P} 23$, é a mudança de densidade de construção nestes locais em comparação com os outros pontos próximos, o que também está relacionado à maior quantidade de áreas permeáveis e a possibilidade de presença de vegetação nos quintais das residências. Amorim (2005) verificou, em estudo na cidade de Presidente Prudente - SP, que a diminuição na densidade de construção produz um efeito pronunciado no que se refere à quebra de continuidade da distribuição das temperaturas mais elevadas.

Na região sul de Curitiba, os pontos $\mathrm{P} 24$ (Rua Francisco Derosso com Rua Coronel Luiz José dos Santos - Xaxim), P25 (Rua Odemir Silveira com Rua Omar Raymundo Piecheth Xaxim) e P26 (Rua Isaac Ferreira da Cruz com Rua Levy Buqueira - Sítio Cercado) apresentaram temperaturas semelhantes à área central. Estes pontos compreendem bairros que tiveram grande crescimento populacional nos últimos anos, com vários conjuntos habitacionais, com tamanho de lotes reduzidos, apresentando pouca vegetação natural e florestas urbanas.

\section{Variação termo-higrométrica no transecto leste- oeste}

No transecto leste-oeste, as maiores diferenças térmicas foram de $1,5^{\circ} \mathrm{C}$ nos períodos

TABELA 2: Temperatura média e umidade relativa do ar média no transecto leste-oeste na área intraurbana de Curitiba nos períodos correspondentes as estações do ano de 2011.

TABLE 2: Average temperature and average relative humidity in the east-west transect in the intra-urban area of Curitiba in the corresponding periods to the seasons of 2011.

\begin{tabular}{|c|c|c|c|c|c|c|c|c|c|c|c|}
\hline \multirow{2}{*}{ Períodos } & \multicolumn{10}{|c|}{ Pontos de monitoramento } & \multirow{2}{*}{ Diferenças } \\
\hline & P6 & $\mathrm{P} 7$ & $\mathrm{P} 8$ & P9 & $\mathrm{P} 10$ & $\mathrm{P} 1$ & $\mathrm{P} 11$ & $\mathrm{P} 12$ & $\mathrm{P} 13$ & P14 & \\
\hline \multicolumn{11}{|c|}{ Temperatura média do ar $\left({ }^{\circ} \mathrm{C}\right)$} & Térmica \\
\hline Verão & $21,7 \mathrm{~cd}$ & $21,4 \mathrm{ab}$ & $21,2 \mathrm{a}$ & $21,7 \mathrm{~cd}$ & $22,0 \mathrm{~d}$ & $21,9 d$ & $21,7 \mathrm{~cd}$ & $21,5 \mathrm{bcc}$ & $22,2 \mathrm{~d}$ & $21,9 \mathrm{~d}$ & 1,2 \\
\hline Outono & $14,7 \mathrm{~b}$ & $14,5 \mathrm{~b}$ & $14,2 \mathrm{a}$ & $15,0 \mathrm{c}$ & $15,1 \mathrm{c}$ & $15,3 \mathrm{c}$ & $15,0 \mathrm{c}$ & $14,8 \mathrm{~b}$ & $15,3 \mathrm{c}$ & $14,7 \mathrm{~b}$ & 1,5 \\
\hline Inverno & $14,7 \mathrm{abc}$ & $14,6 a b$ & $14,3 \mathrm{a}$ & $14,8 \mathrm{bc}$ & $14,9 \mathrm{bc}$ & $15,0 \mathrm{bc}$ & $14,9 \mathrm{bc}$ & $14,7 \mathrm{abc}$ & $15,0 \mathrm{bc}$ & $14,6 \mathrm{ab}$ & 1,2 \\
\hline Primavera & $17,9 \mathrm{bc}$ & $17,9 \mathrm{bc}$ & $17,2 \mathrm{a}$ & $18,1 \mathrm{~cd}$ & $18,2 \mathrm{~cd}$ & $18,3 \mathrm{~cd}$ & $17,7 \mathrm{~b}$ & $17,7 \mathrm{~b}$ & $18,6 \mathrm{e}$ & $17,9 \mathrm{bc}$ & 1,5 \\
\hline \multicolumn{11}{|c|}{ Umidade relativa do ar $(\%)$} & Higrométrica \\
\hline Verão & $83 b$ & $85 \mathrm{a}$ & $85 \mathrm{a}$ & $82 \mathrm{~cd}$ & $81 \mathrm{de}$ & $82 \mathrm{~cd}$ & $82 \mathrm{~cd}$ & $82 \mathrm{~cd}$ & $80 \mathrm{e}$ & $83 b$ & 5 \\
\hline Outono & $81 \mathrm{~cd}$ & $83 b$ & $84 a$ & $79 f g$ & $78 \mathrm{~h}$ & $79 f g$ & $81 \mathrm{~cd}$ & $80 \mathrm{ef}$ & $79 f g$ & $82 \mathrm{bc}$ & 7 \\
\hline Inverno & $77 b$ & $78 \mathrm{a}$ & $79 a$ & $76 \mathrm{bc}$ & $74 d$ & $75 \mathrm{~cd}$ & $77 \mathrm{~b}$ & $75 \mathrm{~cd}$ & $76 b c$ & $79 a$ & 5 \\
\hline Primavera & $74 \mathrm{bc}$ & $76 \mathrm{~b}$ & $78 \mathrm{a}$ & $73 d$ & $71 \mathrm{e}$ & $73 d$ & $75 b$ & $73 d$ & $72 d$ & $76 b$ & 7 \\
\hline
\end{tabular}

Em que: Médias seguidas pela mesma letra na linha (estação do ano) não diferem estatisticamente a 5\% de significância pelo teste de Duncan. 
correspondentes ao outono e primavera, entre os pontos P1 (Praça Tiradentes) e P13 (Rua Vitor Ferreira do Amaral com Linha Verde - Tarumã) com o ponto P8 (Rua Cândido Hartmann com Rua Padre Ladislau Kula - Santo Inácio). As diferenças higrométricas variaram de cinco a sete unidades, com o ponto P8 apresentando a maior umidade relativa do ar em todas as estações do ano (Tabela 2).

Pela Tabela 2 e perfil das temperaturas médias apresentado na Figura 3, foi observado que, no direcionamento leste - oeste, as maiores temperaturas não ocorreram somente na área central da cidade (pontos P10 - Rua Fernando Moreira com Rua Desembargador Motta - Mercês, P1 - Praça Tiradentes e P11 - Rua Ubaldino do Amaral com Rua Visconde de Guarapuava - Alto da Rua XV), mas também no ponto P13, que se refere a uma área de média densidade de construção (SE-BR 116 Setor Especial da BR 116) e com alta circulação de veículos, e ainda próxima à Linha Verde, rodovia com tráfego pesado, demonstrando a influência da circulação de veículos na variação térmica na área urbana de Curitiba. Dumke (2007) afirma que o clima urbano sofre a influência das atividades humanas que liberam um montante adicional de calor, o chamado "calor antropogênico", que nas grandes cidades assume uma ordem de grandeza comparável ao calor gerado pela radiação solar.

O ponto P9 (Rua Euclides da Cunha com Rua Padre Agostinho - Bigorrilho) apresentou temperatura similar à área central. Sua característica é estar localizado no Setor Especial Estrutural $\mathrm{SE}$, com muitos prédios altos e com alto fluxo de
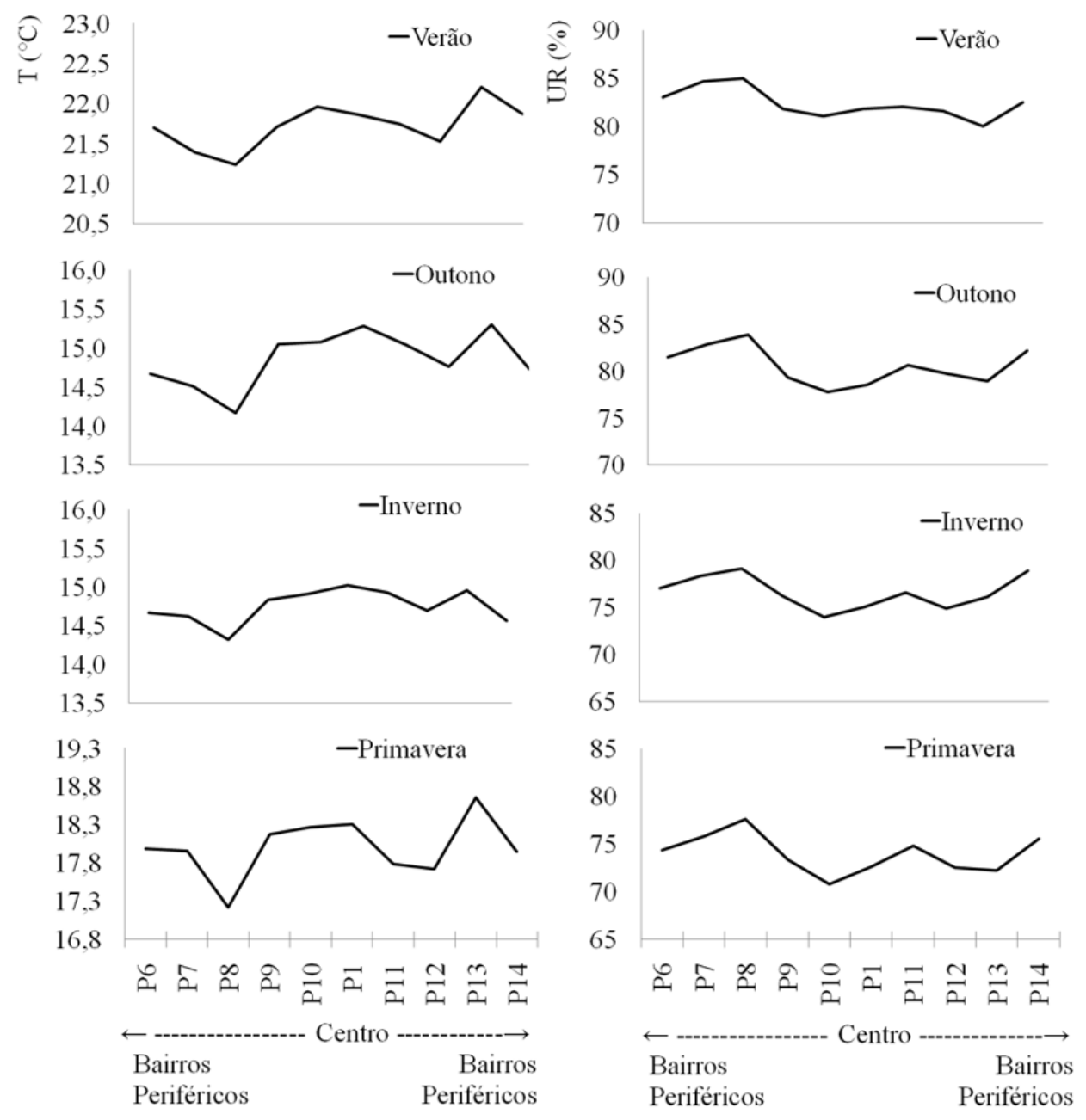

FIGURA 3: Perfil longitudinal da temperatura média e umidade relativa do ar média no transecto leste-oeste na área intraurbana de Curitiba no ano de 2011.

FIGURE 3: Longitudinal profile of the average temperature and average relative humidity in the east-west transect in the intra-urban area of Curitiba in 2011. 
TABELA 3: Temperatura média e umidade relativa do ar média no transecto noroeste-sudeste na área intraurbana de Curitiba nos períodos correspondentes às estações do ano de 2011.

TABLE 3: Average temperature and average relative humidity in the northwest-south-east transect in the intra-urban area of Curitiba in the corresponding periods to the seasons of 2011.

\begin{tabular}{|c|c|c|c|c|c|c|c|c|c|c|c|}
\hline \multirow{2}{*}{ Períodos } & \multicolumn{10}{|c|}{ Pontos de monitoramento } & \multirow{2}{*}{$\begin{array}{l}\text { Diferenças } \\
\text { Térmicas }\end{array}$} \\
\hline & P29 & P30 & P31 & P5 & P1 & P3 & P32 & P33 & P34 & P35 & \\
\hline \multicolumn{12}{|c|}{ Temperatura média do ar $\left({ }^{\circ} \mathrm{C}\right)$} \\
\hline Verão & $21,1 \mathrm{c}$ & $20,9 a$ & $20,9 b$ & $21,9 \mathrm{~d}$ & $21,9 d$ & $22,5 \mathrm{e}$ & $21,9 \mathrm{~d}$ & $21,6 \mathrm{c}$ & $21,6 \mathrm{c}$ & $21,8 \mathrm{~d}$ & 1,6 \\
\hline Outono & $14,1 \mathrm{ab}$ & $14,0 \mathrm{a}$ & $14,3 \mathrm{~b}$ & $15,2 \mathrm{~d}$ & $15,3 \mathrm{~d}$ & $15,7 \mathrm{e}$ & $15,2 \mathrm{~d}$ & $15,0 \mathrm{~cd}$ & $14,8 \mathrm{c}$ & $14,9 \mathrm{c}$ & 1,7 \\
\hline Inverno & $14,3 \mathrm{ab}$ & $14,1 \mathrm{a}$ & $14,3 \mathrm{ab}$ & $14,9 \mathrm{de}$ & $15,0 \mathrm{e}$ & $15,5 \mathrm{f}$ & $14,9 \mathrm{cde}$ & $14,8 \mathrm{cde}$ & $14,6 \mathrm{bcd}$ & $14,5 \mathrm{bc}$ & 1,4 \\
\hline Primavera & $17,5 \mathrm{a}$ & $17,2 \mathrm{a}$ & $17,2 \mathrm{a}$ & $18,0 \mathrm{bc}$ & $18,3 \mathrm{c}$ & $18,6 \mathrm{~d}$ & $18,1 \mathrm{bc}$ & $18,1 \mathrm{bc}$ & $17,9 \mathrm{bc}$ & $17,9 \mathrm{~b}$ & 1,5 \\
\hline \multicolumn{10}{|c|}{ Umidade relativa do ar (\%) } & \multicolumn{2}{|c|}{ Higrométrica } \\
\hline Verão & $84 b$ & $85 \mathrm{ab}$ & $86 a$ & $82 \mathrm{c}$ & $82 \mathrm{c}$ & $78 \mathrm{~d}$ & $83 \mathrm{bc}$ & $83 \mathrm{bc}$ & $83 \mathrm{bc}$ & $83 \mathrm{bc}$ & 7 \\
\hline Outono & $78 \mathrm{~d}$ & $83 a$ & $83 a$ & $80 \mathrm{bc}$ & $79 \mathrm{~cd}$ & $77 \mathrm{e}$ & $79 \mathrm{~cd}$ & $81 \mathrm{~b}$ & $80 \mathrm{bc}$ & $82 a$ & 6 \\
\hline Inverno & $73 \mathrm{e}$ & $78 b$ & $78 \mathrm{~b}$ & $77 \mathrm{bc}$ & $75 \mathrm{~d}$ & $73 \mathrm{e}$ & $76 \mathrm{~cd}$ & $77 \mathrm{bc}$ & $77 \mathrm{bc}$ & $80 \mathrm{a}$ & 7 \\
\hline Primavera & $70 \mathrm{e}$ & $77 \mathrm{ab}$ & $78 \mathrm{a}$ & $75 c$ & $73 \mathrm{de}$ & $71 \mathrm{e}$ & 73de & $75 c$ & 73de & $76 b c$ & 7 \\
\hline
\end{tabular}

Em que: Médias seguidas pela mesma letra na linha (estação do ano) não diferem estatisticamente a 5\% de significância pelo teste de Duncan.

veículos, além de estar próximo de Zona Residencial de Média Densidade - ZR-3.

As menores temperaturas e a maior umidade relativa do ar não ocorreram nos pontos extremos deste transecto (Tabela 2 e Figura 3). Observou-se uma forte diminuição da temperatura e um aumento da umidade relativa do ar no ponto $\mathrm{P} 8$ (Rua Cândido Hartmann com Rua Padre Ladislau Kula - Santo Inácio), localizado a cerca de $500 \mathrm{~m}$ do Parque Municipal Barigui, grande área verde com $1.400 .000 \mathrm{~m}^{2}$, que inclui cobertura florestal e lago, fatores amenizadores climáticos, além de outros remanescentes florestais próximos e residências com jardins e quintais, possibilitados pelo zoneamento de uso do solo. Segundo Oliveira (1996), a presença de um grande lago é uma característica comum na maioria dos parques municipais de Curitiba. Além dos efeitos da vegetação no microclima, $\mathrm{Xu}$ et al. (2010) indicam a presença de corpos d'água na malha urbana como importante fator amenizador climático. Outro aspecto analisado foi a alteração da densidade de ocupação, que no ponto $P 8$ é de baixíssima a baixa densidade (ZR-1 e ZR$2)$, enquanto nos pontos adjacentes é de média densidade.

Também no ponto P12 (Av. Marechal Humberto de A. C. Branco com Rua Vitor Ferreira do Amaral - Cristo Rei) foi verificada uma redução na temperatura média do ar, porém, menos intensa do que no ponto P8. Neste caso também há menor densidade de construções e proximidade com outra tipologia de floresta urbana, a Praça das Nações, além da arborização de ruas com árvores de grande porte, principalmente Tipuana tipu (Benth.) Kuntze (tipuana).

\section{Variação termo-higrométrica no transecto noroeste-sudeste}

No transecto noroeste-sudeste foram encontradas diferenças térmicas entre $1,5^{\circ} \mathrm{C}$ (primavera) e $1,7^{\circ} \mathrm{C}$ (outono) entre os pontos de monitoramento (Tabela 3). O ponto P3 (Rua André de Barros com Rua Barão do Rio Branco - Centro), localizado em área central consolidada, altamente impermeabilizada e com grande circulação de veículos, foi o local de maior temperatura e de menor umidade relativa do ar. Enquanto as menores temperaturas ocorreram nos pontos P29 (Rua Fredolin Wolf com Rua Saturnino de Miranda - Lamenha Pequena), P30 (Rua José Vale - São João) e P31 (Rua Jacarezinho com Rua Solimões - Vista Alegre), localizados na porção noroeste do município, em áreas residenciais e na região que concentra a maior quantidade de cobertura vegetal, conforme Vieira e Biondi (2008).

Na Figura 4 é visualizado que as menores temperaturas foram encontradas nos pontos extremos do lado noroeste com maior cobertura vegetal, com os pontos $\mathrm{P} 30$ e $\mathrm{P} 31$, respectivamente, próximos ao Parque Municipal Tingui e o Bosque Gutierrez. 
No lado sudeste não houve a mesma intensidade de redução de temperatura na área limítrofe, principalmente no ponto P35 (Rua Velci Bolívar Grando com Rua Amauri Mauad Gueiros - Uberaba). Esperava-se uma maior redução de temperatura neste ponto, por estar relativamente próximo (cerca de $1 \mathrm{~km}$ ) do Parque Municipal Iguaçu (área de $8.264 .316 \mathrm{~m}^{2}$ ), o que não ocorreu. Isto pode ser explicado pelo ponto P35 estar localizado em Setor Especial de Habitação de Interesse Social SEHIS, referente ao conjunto habitacional com tamanho de lote reduzido, com pouca arborização de ruas e ausências de praças com árvores. Outro fator é a continuidade da área urbana para fora dos limites de Curitiba pela conurbação com o município de
São José dos Pinhais, pelas Avenidas das Torres e Rui Barbosa, conforme Pilotto (2010). O ponto P35, no entanto, está entre os de maior umidade relativa do ar neste transecto, pela provável influência da vegetação e hidrografia próxima.

\section{Variação termo-higrométrica no transecto sudoeste-nordeste}

No transecto sudoeste-nordeste, a maior diferença térmica $\left(1,1^{\circ} \mathrm{C}\right)$ foi verificada no período do outono (Tabela 4), entre o ponto P1 (Praça Tiradentes - Centro), na área central consolidada, e o ponto P44 (Rua Estrada das Olarias com Rua Arnaldo W. Gaensli - Santa Cândida), no limite

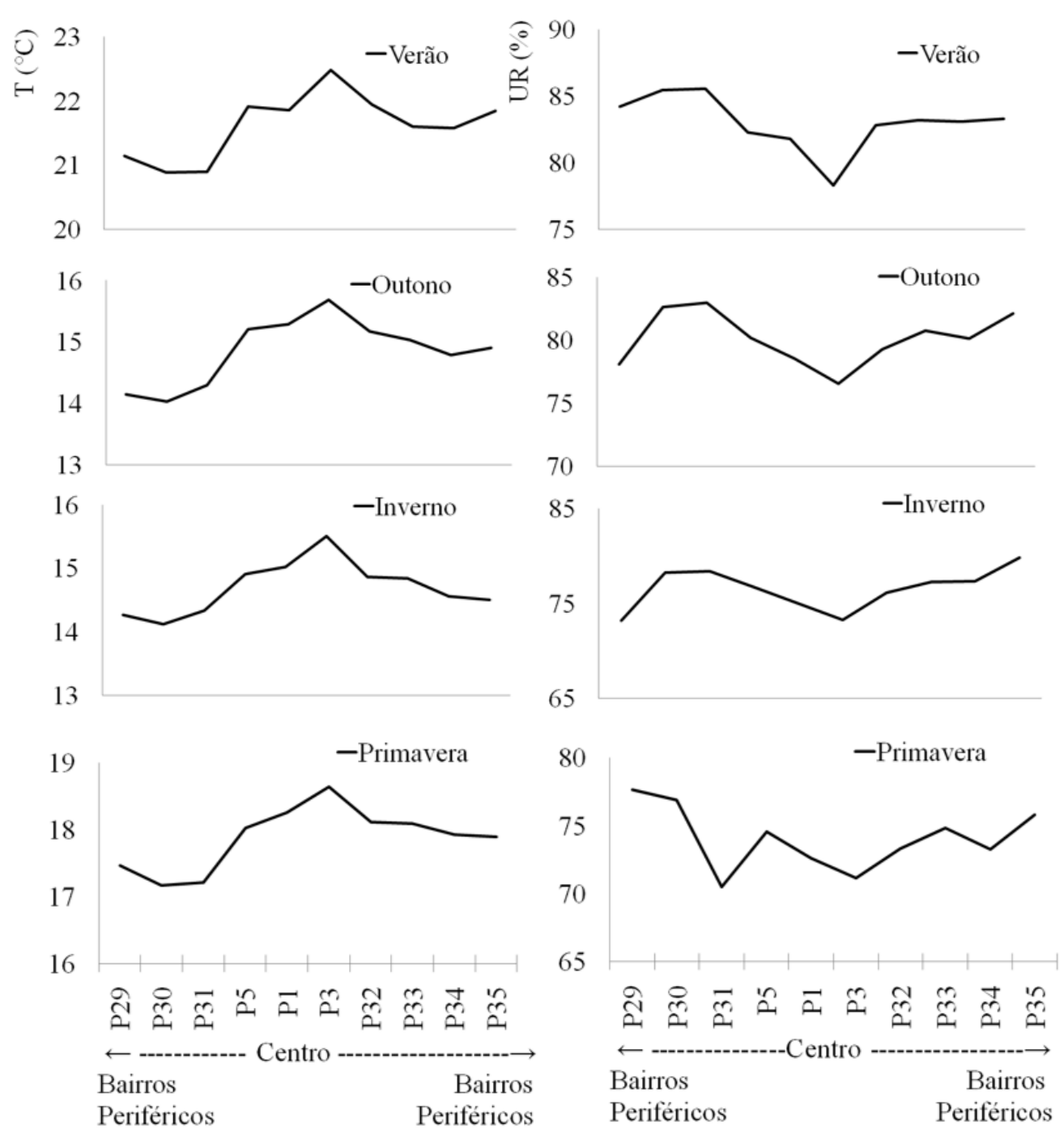

FIGURA 4: Perfil longitudinal da temperatura média e umidade relativa do ar média no transecto noroestesudeste na área intraurbana de Curitiba no ano de 2011.

FIGURE 4: Longitudinal profile of the average temperature and average relative humidity in the northwestsoutheast transect in the intra-urban area of Curitiba in 2011. 
TABELA 4: Temperatura média e umidade relativa do ar média no transecto sudoeste-nordeste na área intraurbana de Curitiba nos períodos correspondentes às estações do ano de 2011.

TABLE 4: Average temperature and average relative humidity in the south-west-northeast transect in the intra-urban area of Curitiba in the corresponding periods to the seasons of 2011.

\begin{tabular}{|c|c|c|c|c|c|c|c|c|c|c|c|c|c|}
\hline \multirow{2}{*}{ Períodos } & \multicolumn{12}{|c|}{ Pontos de monitoramento } & \multirow{2}{*}{ Variação } \\
\hline & P36 & P37 & P38 & P39 & $\mathrm{P} 40$ & P2 & $\mathrm{P} 1$ & P4 & P41 & P42 & P43 & P44 & \\
\hline \multicolumn{13}{|c|}{ Temperatura média do $\operatorname{ar}\left({ }^{\circ} \mathrm{C}\right)$} & Térmica \\
\hline Verão & $\begin{array}{c}21,9 \\
\mathrm{~cd}\end{array}$ & $\begin{array}{c}21,8 \\
b c\end{array}$ & $\begin{array}{c}21,8 \\
b c\end{array}$ & $\begin{array}{c}21,8 \\
b c\end{array}$ & $\begin{array}{l}21,7 \\
a b c\end{array}$ & $\begin{array}{c}21,8 \\
b c\end{array}$ & $\begin{array}{c}21,9 \\
\mathrm{~cd}\end{array}$ & $\begin{array}{c}22,1 \\
\mathrm{e}\end{array}$ & $\begin{array}{c}21,6 \\
a b\end{array}$ & $\begin{array}{c}21,6 \\
a b\end{array}$ & $\begin{array}{c}21,5 \\
a\end{array}$ & $\begin{array}{c}21,6 \\
a b\end{array}$ & 0,6 \\
\hline Outono & $\begin{array}{c}15,0 \\
\mathrm{~cd}\end{array}$ & $\begin{array}{c}15,2 \\
\text { de }\end{array}$ & $\begin{array}{c}15,0 \\
\mathrm{~cd}\end{array}$ & $\begin{array}{c}14,9 \\
\text { bc }\end{array}$ & $\begin{array}{l}15,1 \\
\text { cde }\end{array}$ & $\begin{array}{l}15,1 \\
\text { cde }\end{array}$ & $\begin{array}{c}15,3 \\
\mathrm{e}\end{array}$ & $\begin{array}{l}15,1 \\
\text { cde }\end{array}$ & $\begin{array}{c}14,6 \\
b\end{array}$ & $\begin{array}{c}14,9 \\
b c\end{array}$ & $\begin{array}{c}14,7 \\
b\end{array}$ & $\begin{array}{c}14,2 \\
a\end{array}$ & 1,1 \\
\hline Inverno & $\begin{array}{c}14,6 \\
a b\end{array}$ & $\begin{array}{l}14,8 \\
\text { bcd }\end{array}$ & $\begin{array}{c}14,7 \\
b c\end{array}$ & $\begin{array}{l}14,8 \\
\text { bcd }\end{array}$ & $\begin{array}{c}14,7 \\
b c\end{array}$ & $\begin{array}{c}15,1 \\
\mathrm{~d}\end{array}$ & $\begin{array}{c}15,0 \\
\mathrm{~cd}\end{array}$ & $\begin{array}{c}15,1 \\
\mathrm{~d}\end{array}$ & $\begin{array}{c}14,5 \\
a b\end{array}$ & $\begin{array}{c}14,6 \\
a b\end{array}$ & $\begin{array}{c}14,6 \\
a b\end{array}$ & $\begin{array}{c}14,2 \\
\mathrm{a}\end{array}$ & 0,9 \\
\hline Primavera & $\begin{array}{l}18,2 \\
\text { bcd }\end{array}$ & $\begin{array}{c}18,4 \\
\mathrm{~cd}\end{array}$ & $\begin{array}{l}18,3 \\
\text { bcd }\end{array}$ & $\begin{array}{l}18,2 \\
\text { bcd }\end{array}$ & $\begin{array}{l}18,0 \\
a b c\end{array}$ & $\begin{array}{l}17,9 \\
a b c\end{array}$ & $\begin{array}{l}18,3 \\
\text { bcd }\end{array}$ & $\begin{array}{c}18,6 \\
\mathrm{~d}\end{array}$ & $\begin{array}{c}17,6 \\
\mathrm{a}\end{array}$ & $\begin{array}{c}17,9 \\
\mathrm{ab}\end{array}$ & $\begin{array}{c}17,6 \\
\mathrm{a}\end{array}$ & $\begin{array}{c}17,9 \\
\mathrm{ab}\end{array}$ & 1,0 \\
\hline \multicolumn{13}{|c|}{ Umidade relativa do ar $(\%)$} & Higrométrica \\
\hline Verão & $85 \mathrm{ab}$ & $83 \mathrm{c}$ & $84 \mathrm{bc}$ & $82 \mathrm{~cd}$ & $80 \mathrm{de}$ & $76 f$ & $82 \mathrm{~cd}$ & $81 \mathrm{~d}$ & $84 \mathrm{bc}$ & $84 \mathrm{bc}$ & $86 \mathrm{a}$ & $84 b c$ & 10 \\
\hline Outono & $78 \mathrm{~g}$ & $79 \mathrm{f}$ & $81 \mathrm{~d}$ & $80 \mathrm{e}$ & $78 \mathrm{~g}$ & $78 \mathrm{~g}$ & $79 f$ & $80 \mathrm{e}$ & $83 b$ & $82 \mathrm{c}$ & $80 \mathrm{e}$ & $84 a$ & 6 \\
\hline Inverno & 76de & $76 \mathrm{de}$ & $78 \mathrm{bc}$ & 76de & $75 \mathrm{ef}$ & $74 f$ & $75 \mathrm{ef}$ & $77 \mathrm{~cd}$ & $79 \mathrm{ab}$ & $79 b$ & $77 \mathrm{~cd}$ & $80 \mathrm{a}$ & 6 \\
\hline Primavera & $72 \mathrm{de}$ & $72 \mathrm{de}$ & $75 b c$ & $73 d$ & $72 \mathrm{de}$ & $72 \mathrm{de}$ & $73 d$ & $73 d$ & $78 \mathrm{a}$ & $76 b$ & $75 \mathrm{bc}$ & $76 b$ & 6 \\
\hline
\end{tabular}

Em que: Médias seguidas pela mesma letra na linha (estação do ano) não diferem estatisticamente a 5\% de significância pelo teste de Duncan.

nordeste. Em geral, as maiores temperaturas foram encontradas, além do ponto $\mathrm{P} 1$, nos pontos $\mathrm{P} 40$ (Avenida Sete de Setembro com Rua Castro Alves - Batel), P2 (Rua Visconde de Nácar com Rua Emiliano Perneta - Centro) e P4 (Rua Luis Leão com Rua Conselheiro Araújo - Centro), localizados, respectivamente, em Setor Estrutural (SE), Zona Central (ZC) e Zona Residencial de Média-Alta Densidade (ZR-4).

$\mathrm{Na}$ Figura 5 verifica-se que no lado nordeste deste transecto, além dos pontos extremos, no ponto P41 (Rua Jaime Balão com Via Férrea - Bairro Hugo Lange) ocorreu redução de temperatura e aumento da umidade relativa do ar. Isto pode ser explicado pela alteração do zoneamento, que nos pontos próximos é de média-alta a média densidade (ZR-4 e ZR-3), enquanto que no ponto P41 é de baixíssima densidade (ZR-1). Também este ponto está próximo a várias praças com canteiro gramado e árvores.

As temperaturas na porção nordeste foram menores do que na porção sudoeste (Figura 5). Isto é explicado pelo uso do solo nestas regiões, pois enquanto a nordeste possui maior concentração de florestas urbanas, na sudoeste há menor quantidade de florestas, além da sua proximidade com áreas industriais, no bairro Cidade Industrial de Curitiba, que se liga espacialmente com o Centro Industrial do município de Araucária.

Os pontos P36 (Rua Raul Pompeia com Rua Ludovico Kaminski - CIC) e P37 (Rua Raul Pompeia com Rua João Debimski - Fazendinha), apesar de estarem localizados na área limítrofe deste transecto, não ficaram dentre os pontos de menor temperatura. Estes locais possuem média densidade de ocupação, sendo que o ponto P37 está localizado no Setor Especial de Habitação de Interesse Social - SEHIS, com lote de tamanho reduzido, e o ponto P36 em Zona de Uso Misto - ZUM, com média densidade habitacional, de apoio residencial às zonas industriais e de serviços. Mendonça e Dubreuil (2005), com análise de imagem termal, verificaram que as áreas no bairro Cidade Industrial de Curitiba acumulam maior calor devido às suas superfícies mineralizadas e de menor albedo que as áreas vizinhas.

O ponto P40 (Avenida Sete de Setembro com Rua Castro Alves - Batel), localizado em área verticalizada, apesar de situar-se próximo à área central consolidada, apresentou redução da temperatura média, exceto no período correspondente ao inverno, se comparado aos 


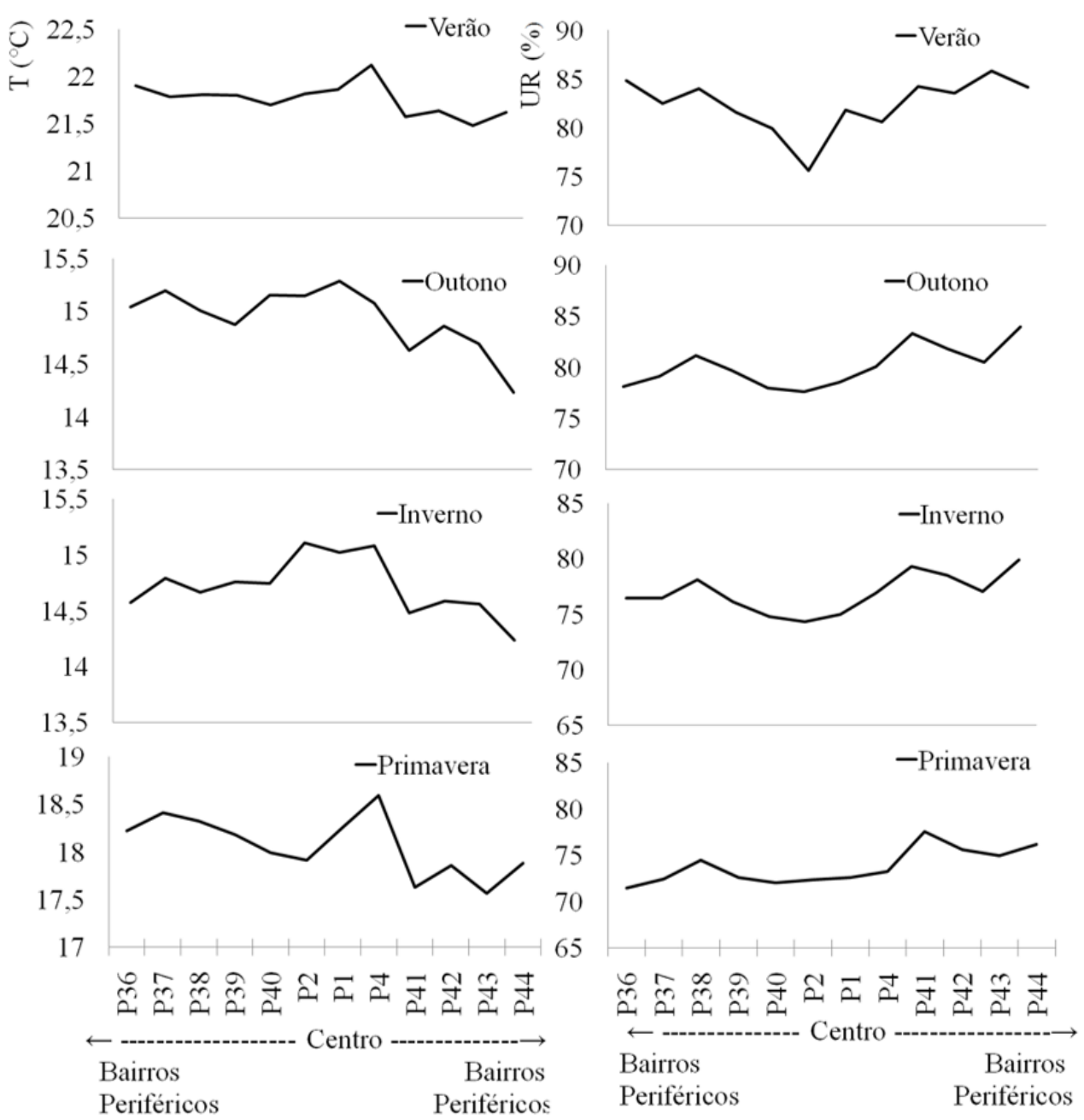

FIGURA 5: Perfil longitudinal da temperatura média e umidade relativa do ar média no transecto sudoestenordeste na área intraurbana de Curitiba no ano de 2011.

FIGURE 5: Longitudinal profile of the average temperature and average relative humidity in the southwestnortheast transect in the intra-urban area of Curitiba in 2011.

pontos da área central, o que pode estar relacionado com a massa térmica das edificações e radiação solar barrada pelo sombreamento dos prédios. Dumke (2007) também verificou menor temperatura em ponto de monitoramento no bairro Batel devido à influência da verticalização na insolação e o efeito da topografia natural somado ao da topografia edificada, favorecendo a ventilação.

\section{CONCLUSÕES}

Os resultados obtidos nesta pesquisa comprovam o efeito do calor antropogênico proveniente da estrutura urbana composta por superfície impermeável das edificações e revestimentos das ruas, visto que foram encontradas diferenças termo-higrométricas significativas entre os pontos de monitoramento em todos os períodos analisados.

Com o monitoramento de todos os pontos analisados foi possível constatar a existência da ilha de calor urbano caracterizada pelas maiores temperaturas nos locais com maior intensidade de ocupação e concentração de atividades antrópicas e as menores temperaturas em bairros residenciais e periféricos, com menor densidade de construção.

A presença de diferentes tipologias de florestas urbanas provocou quebras na continuidade de altas temperaturas na área urbana, mostrando o importante papel dos espaços verdes públicos no clima local da cidade de Curitiba. 


\section{AGRADECIMENTOS}

À Fundação Araucária de Apoio ao Desenvolvimento Científico e Tecnológico do Paraná pelo financiamento dessa pesquisa.

À Urbanização de Curitiba S.A. (URBS) pela permissão da instalação dos miniabrigos meteorológicos nas estruturas urbanas.

\section{REFERÊNCIAS BIBLIOGRÁFICAS}

ANDRADE, H. O clima urbano - Natureza, escalas de análise e aplicabilidade. Finisterra, Lisboa, v. 40, n. 80, p. 67-91, 2005.

AMORIM, M. C. C. T. Intensidade e forma da ilha de calor urbana em Presidente Prudente/SP: episódios de inverno. Geosul, Florianópolis, v. 20, n. 39, p. 65-82, 2005.

DIMOUDI, A.; NIKOLOPOULOU, M. Vegetation in the urban environment: microclimatic analysis and benefits. Energy and Buildings, Lausanne, n. 35, p. 69-76, 2003.

DUMKE, E. M. S. Clima urbano / conforto térmico e condições de vida na cidade - uma perspectiva a partir do aglomerado urbano da região metropolitana de Curitiba (AU-RMC). 417 f. Tese (Doutorado em Meio Ambiente e Desenvolvimento) - Universidade Federal do Paraná, Curitiba, 2007.

ELIASSON, I. The use of climate knowledge in urban planning. Landscape and Urban Planning, Amsterdam, v. 48, p. 31-44, 2000.

FORTUNIAK, K.; KLYSIK, K.; WIBIG, J. Urbanrural contrasts of meteorological parameters in Lodz. Theor. Appl. Climatol., Viena, v. 84, p. 91-101, 2006.

GARTLAND, L. Ilhas de calor: como mitigar zonas de calor em áreas urbanas. São Paulo: Oficina de Textos, 2010. 223 p.

GRIMMOND, S. Urbanization and global environmental change: local effects of urban warming. In: The Royal Geographical Society, London, 2007. p. 83-88.

GOMES, M. A. S.; AMORIM, M. C. C. T. Arborização e conforto térmico no espaço urbano: estudo de caso nas praças públicas de Presidente Prudente (SP). Caminhos da Geografia, Uberlândia, v. 7, n. 10, p. 94-106, 2003.

GONÇALVES, W.; PAIVA, H. N. Silvicultura Urbana: implantação e manejo. Viçosa: Aprenda Fácil, 2006. 201 p.

KOLOKOTRONI, M.; GIANNITSARIS, I.; WATKIN, R. The effect of the London urban heat island on building summer cooling demand and night ventilation strategies. Solar Energy, Kidlington, v. 80, p. 383-392, 2006.

INSTITUTO DE PESQUISA E PLANEJAMENTO URBANO DE CURITIBA. Curitiba em dados. Disponível em: <http://ippucnet.ippuc.org.br/ bancodedados/curitibaemdados/curitiba_em dados_pesquisa.asp> Acesso em: 19 janeiro 2012.

LEAL, L. A influência da vegetação no clima urbano da cidade de Curitiba - PR. 172 f. Tese (Doutorado em Engenharia Florestal) Universidade Federal do Paraná. Curitiba, 2012.

MENDONÇA, F. A.; DANNI-OLIVEIRA, I. M. Climatologia: noções básicas e climas do Brasil. São Paulo: Oficina de Texto, 2007. 206 p. v.1.

MENDONÇA, F. A.; DUBREUIL, V. Termografia de superfície e temperatura do ar na RMC (região metropolitana de Curitiba / PR). R. Ra'ega, Curitiba, n. 9, p. 25-35, 2005.

MILLER, R.W. Urban Forestry: Planning and managing urban greenspaces. 2nd ed. New Jersey: Prentice-Hall, 1997. 502 p.

OKE, T. R. Review of urban climatolology: 1973 1976. WMO Technical Note, Geneve, n.169, 1974. OKE, T. R. The distinction between canpoy layer and boundary-layer urban heat islands. Atmosphere, v. 14 , n. 4 , p. $268-277,1976$.

OKE, T. R. Siting and exposure of meteorological instruments at urban sites. In: BORREGO, C.; NORMAN, A. Air pollution modeling and its application XVII. New York: Springer, 2007. p. 615-631.

OLIVEIRA, M. Perfil ambiental de uma metrópole brasileira: Curitiba, seus parques e bosques. Revista Paraná Desenvolv., Curitiba, n. 88, maio/ago. p. 37-54, 1996.

PREFEITURA MUNICIPAL DE CURITIBA. Áreas Verdes. 2011. Disponível em $<$ http://www.curitiba.pr.gov.br/publico/secretaria. aspx idf $=396 \&$ servico $=26>$ Acesso em: 10 junho 2011.

PILOTTO, A. S. Área metropolitana de Curitiba: um estudo a partir do espaço intraurbana. 196 f. Dissertação (Mestrado em Planejamento Urbano) - Faculdade de Arquitetura e Urbanismo, Universidade de São Paulo, São Paulo, 2010.

SPROKEN-SMITH, R. A; OKE, T. R. Scale modelling of nocturnal cooling in urban parks. Boundary-Layer Meteorology, Dordrecht, v. 93, p. 287-312, 1999.

UPMANIS, H., ELIASSON, I., LINDQVIST, S. The influence of green areas on nocturnal temperatures 
in a high latitude city (Goeteborg, Sweden). Int. J. 31 julho 2009.

Climatol., Malden, v. 18, p. 681-700, 1998.

VIEIRA, C. H. S. D.; BIONDI, D. Análise da dinâmica da cobertura vegetal de Curitiba, PR (de 1986 a 2004), utilizando imagens Landsat TM. Árvore, Viçosa, v. 32, n. 3, p. 479-487, 2008.

WORLD METEOROLOGICAL ORGANIZATION. Guide to meteorological instruments and methods of observation. 7.nd. Geneva: WMO, 2008. Disponível em: <http://www.wmo.int/pages/ prog/www/IMOP/publications/CIMO-Guide/ CIMO_Guide-7th_Edition-2008.html $>$ Acesso em:
WONG, N. H.; YU, C. Study of green areas and urban heat island in a tropical city. Habitat International, Oxford, v. 29, p. 547-558, 2005.

XU, J.; WEI, Q.; HUANG, X.; ZHU, X.; GUANGMING, L. Evaluation of human thermal comfort near urban waterbody during summer. Building and Environment, Oxford, v. 45, p. 1072-1080, 2010.

YU, C.; HIEN, W. N. Thermal benefits of city parks. Energy and Buildings, Lausanne, v. 38, p. 105120, 2006. 